\title{
Educação da audição e valores estéticos na filosofia da nova música de Theodor Adorno
}

\author{
Hearing education and aesthetical values in the philosophy of the new music of Theodor \\ Adorno
}

\begin{abstract}
Alan Barcelos Ribeiro ${ }^{1}$
Carlos Betlinski ${ }^{2}$

\section{Resumo}

O artigo trata da "Filosofia da Nova Música" de Theodor Adorno e tem como problema de investigação saber quais são os valores estéticos apresentados pelo autor para identificar Schoenberg como o representante do progresso musical. Como objetivos específicos para esse trabalho foram definidos: a identificação das principais características estéticas nas obras musicais de Stravinsky e de Schoenberg e apontar alguns fundamentos filosóficos para diferenciar progresso e regressão na estética musical de Adorno. Ao caracterizar sua concepção estética como filosofia da arte, Adorno toma a produção e a recepção como expressões de uma relação dialética com o meio social e tece críticas especialmente a indústria cultural e a arte burguesa que tinham como propósito agradar o ouvido e permitir que os produtores e receptores estabelecessem uma relação de troca no mercado capitalista. Por isso, sua estética está assentada na crítica e na possibilidade de criação dissonante e autônoma, análises que foram realizadas no âmbito desta investigação que tem como foco a questão da música enquanto objeto estético de progresso ou regressão da audição.
\end{abstract}

Palavras-chaves: Estética. Música. Educação musical.

\begin{abstract}
The article has to do with Theodor Adorno's "Philosophy of the New Music" and aims at investigating the aesthetic values presented by the author so as to identify Schoenberg as the representative of musical advancement. The specific objectives for this work were defined: the identification of the main aesthetic characteristics in the musical pieces of Stravinsky and Schoenberg as well as highlighting some philosophical basis to differentiate progress and regression in the musical aesthetics of Adorno. Characterizing his aesthetic conception as philosophy of art, Adorno takes the production and reception of art as expressions of a dialectical relationship with the social milieu criticizing mainly the cultural industry and bourgeois art which were intended to please the ear and allow producers and recipients to establish an exchange rapport in the capitalist market. Therefore, his aesthetics is based upon the criticism and the possibility of dissonant and autonomous creation, analysis that were

\footnotetext{
${ }^{1}$ Mestre em Educação pelo Programa de Pós-graduação em Educação da UFLA - Universidade Federal de Lavras. Professor de música no Conservatório Estadual Conservatório Estadual de Música Juscelino Kubistchek de Oliveira - Pouso alegre/MG, Brasil. E-mail: alan.piano@yahoo.com.br

2 Doutor em Educação pela PUC/SP. Professor do Programa de Pós-Graduação em Educação da UFLA. Lavras/MG, Brasil. E-mail:carlosbetlinski@ufla.br
} 
carried out within the scope of such investigation that focuses on the issue of music as an aesthetic object of progress or regression of hearing.

Keywords: Aesthetics. Music. Musical education.

\section{Introdução}

Este artigo se propõe a apresentar as características estéticas da música de Stravinsky e Schoenberg a partir da interpretação da Filosofia da nova música de Theodor Adorno e com isso, contribuir para a educação da audição em tempos da indústria cultural.

Para cumprir com os objetivos anteriores fundamentamos nossas interpretações a partir de Adorno que adota dois extremos na análise da produção musical para apontar os modelos de música que induz os homens à regressão de um lado, e ao progresso de outro: respectivamente encontramos Igor Stravinsky e Arnold Schoenberg como representantes desses modelos. Notamos que em Stravinsky, Adorno vislumbra a presença de um reacionário, aparentemente inovador, no entanto, suas produções mantêm o conservadorismo do tonalismo e uma tentativa malograda de resgatar o primitivismo musical de maneira fragmentada e desconectada do curso evolutivo histórico. Por outro lado, em Schoenberg, Adorno vislumbra o progresso, a inovação representada pelo atonalismo, uma nova concepção musical que foge às regras do conservadorismo tradicional tonal, a partir da qual há o desencadeamento de novas técnicas composicionais como o dodecafonismo e o serialismo.

A partir dessas constatações consideramos que o pensamento de Adorno apresenta um novo modelo de se conceber a estética. Os fenômenos sociais, o percurso histórico, a capacidade crítica e reflexiva humana são elementos que vêm agregar às questões estéticas, contribuindo para uma produção artística que assegura a autonomia da Arte e colabora para o progresso do desenvolvimento artístico cognitivo.

A análise filosófica aqui realizada perpassa questões centrais para a teoria crítica da sociedade, especialmente no que diz respeito à questão estética da inseparabilidade entre forma e do conteúdo e da questão epistemológica da relação dialética entre sujeito e objeto. Essas questões são tratadas com profundidade por Adorno, e estão presente especialmente em sua obra Teoria estética.

Ao considerar que as obras de arte são expressões dialéticas do produtor e da cultura histórica e que, portanto, o artista sedimenta em sua obra o conteúdo social e, ao mesmo 
tempo a forma de expressão estética e a técnica utilizada contribui para o progresso cognitivo, Adorno define outros critérios e valores estéticos que não aqueles vinculados à tradição e à produção do mercado capitalista. O primeiro, conservador da tradição e dos valores cristalizados pela sociedade; o segundo, vinculado aos interesses de agradar e produzir o "bom gosto" segundo a lógica de agradar ao público.

Sobre a questão epistemológica permeada pela dialética entre sujeito e objeto do conhecimento Adorno considera que o objeto se apresenta como primazia e na relação estabelecida se revela ou demanda que o sujeito capture suas características enquanto fenômeno social. Nessa relação, cabe ao sujeito o esforço de interpretação e de fazer ressaltar propriedades do objeto sem preconceitos ou sem a absolutização da razão. O que se estabelece é uma relação inconclusa, aberta, sempre havendo possibilidades de renovação do pensamento diante da apresentação de novos dados ou de leituras a partir de novas perspectivas cognitivas.

O problema proposto para nossa pesquisa está centrado na seguinte preocupação: quais valores estéticos são apontados por Adorno para eleger Schoenberg como representante da filosofia da nova música?

Como objetivos para essa investigação definimos: identificar as principais características estéticas nas obras musicais de Stravinsky e de Schoenberg segundo as proposições de Adorno; apontar alguns fundamentos filosóficos para diferenciar progresso e regressão na estética musical de Adorno.

O esforço empreendido para responder ao problema desta investigação e também para atingir os objetivos propostos seguiu o método dialético procurando ressaltar aspectos que o próprio autor utilizou para caracterizar tanto a obra de Stravinsky, quanto de Schoenberg. A leitura de obras complementares como "Teoria estética" e "O fetichismo na música e a regressão da audição" de Theodor Adorno contribuíram significativamente para que pudéssemos atingir os objetivos propostos para este trabalho.

Organizamos nossa exposição a partir das seguintes etapas ou encaminhamentos: No primeiro momento apresentamos alguns elementos que corroboram para a compreensão da obra "Filosofia da Nova música" de Adorno, um texto central para a análise da sua estética musical; no segundo momento analisamos as características musicais de Stravinsky a partir das considerações de Adorno, com destaque para as considerações que elabora sobre a regressão; no terceiro momento, apontamos questões relativas à forma e conteúdo da estética 
musical de Schoenberg com os apontamentos de Adorno no sentido de considerá-lo como representante da nova música.

\section{Breves considerações sobre a obra Filosofia da nova música}

O texto Filosofia da Nova Música de Theodor W. Adorno, publicada pela primeira vez em 1949, e logo no seu prefácio encontra-se a explicação de que se trata da união de dois trabalhos do filósofo: um estudo sobre a produção musical de Igor Stravinsky e outro sobre a produção musical de Arnold Schoenberg.

Em 1940, Adorno, continuando as reflexões iniciadas em seu texto $O$ fetichismo da música e a regressão da audição (1938), produz o texto Schoenberg e o progresso, porém, este trabalho não é publicado e seu acesso fica restrito. Após sete anos ele decide publicá-lo, no entanto vislumbra a necessidade de produzir algo que contrapusesse suas considerações sobre Schoenberg, então escreve o texto Stravinsky e a restauração. Ambos os textos compõem a obra final intitulada Filosofia da Nova Música.

Uma obra tão complexa e sinuosa quanto pedem os padrões de erudição do filósofo, estudioso de filosofia, da sociologia, da literatura, da música e psicanalista social. Esse texto apresenta a maneira crítica e dialética de escrever, sempre estruturada numa rigidez conceitual constelatória, subentendendo que seu leitor tenha conhecimento prévio sobre vários assuntos. O frankfurtiano se utiliza de um requintado vocabulário musical que ampara suas metáforas e analogias permeadas por seu modo erudito de interpretar a história da música, sem perder de vista seu olhar crítico, estético e social.

Adorno demonstra que um tratamento filosófico sobre a natureza da música moderna é evidenciado unicamente pelos extremos e somente estes permitem reconhecer o seu conteúdo de verdade (ADORNO, 2011, p.13). Nesta perspectiva, considera que Stravinsky e Schoenberg representam os extremos do movimento da nova música ${ }^{3}$, não por um juízo de

\footnotetext{
${ }^{3}$ A nova música aqui está sendo considerado como um movimento cultural marcado por novas atitudes sociais, morais, econômicas e políticas que, envolta da produção musical, instiga novas experiências sonoras, novas técnicas composicionais e até mesmo uma transformação na própria linguagem musical. É no contexto da nova música que emergem novas vertentes musicais como o neoclassicismo, o expressionismo, o serialismo integral, o minimalismo, a micropolifonia, os extratos sonoros, a música concreta, as músicas expectrais e a nova complexidade. Na opinião de Adorno esta nova música é o exemplo de arte que sobrevive enquanto arte, já que não é atingida pela indústria cultural pelo menos no aspecto da comercialização e consumo pela massa.
} 
valor ou gosto, mesmo por que vários outros compositores deste mesmo segmento apresentaram produções superiores às de ambos.

Adorno situa Stravinsky como regressão, em um extremo oposto a Schoenberg, no sentido ideológico de seus princípios, porque julga a obra de Stravinsky baseada predominantemente no quesito de uso do sistema tonal. Entretanto, vale destacar que a parte rítmica, selvagem e brutal, com suas quiálteras ${ }^{4}$ alucinantes, constantes mudanças de compasso, polimetrias e o uso de melodias diferentes simultaneamente, fazem de Stravinsky um vanguardista. Evidentemente esses procedimentos já eram usados na Idade Média, mas não da maneira proposta por Stravinsky, portanto, original.

Pois bem, a capacidade dialética adorniana permite considerar Stravinsky e Schoenberg como "dois inovadores, não porque a eles corresponda a prioridade histórica e os demais derivem deles, mas porque somente eles, por uma coerência que não conhece concessões, exaltaram os impulsos presentes em suas obras até transformá-las nas ideias imanentes do objeto" (ADORNO, 2011, p. 14).

Importante ressaltar que a proposta de tratamento filosófico da arte musical sugerida por Adorno, se refere à Arte propriamente dita e não aos seus conceitos de estilos, formas e gosto. Para Adorno a "arte tem o seu conceito na constelação de momentos que se transformam historicamente" tendo em vista que a mesma "só é interpretável pela lei do seu movimento, não por invariantes" (ADORNO, 2013, p. 13-14). Assim, compartilhamos da ideia de que a arte se apresenta como autossuficiente, porém, não se desvencilha da realidade social em que se apresenta. É o que afirma Sergio Schaefer, em sua tese de doutorado intitulada A teoria estética em Adorno ao sustentar que

\begin{abstract}
A arte se apresenta com um caráter fortemente ambíguo: á autônoma e é um fato social. Como autônoma não depende de nenhuma força produtiva e, por isso, não estabelece relações de produção estética. Como fait social, se encontra inserida tanto na teleologia do trabalho e do fazer estéticos quanto se emaranha numa rede de relações. Dessas relações emergem antagonismos não resolvidos - tanto contradições, como oposições - que são trazidas para dentro das obras de arte e nelas fervilham, borbulham, remexem de forma imanente, tornam-se problemas imanente da forma estética. É isso que faz a arte inserir-se no social. (SCHAEFER, 2012, p. 30).
\end{abstract}

Assim sendo, as reflexões e considerações apresentadas pelo frankfurtiano sobre a produção musical de Schoenberg e Stravinsky, no contexto da Filosofia da nova música, ultrapassam a discussão sobre a atonalidade, a técnica dodecafônica ou o neoclassicismo para

\footnotetext{
${ }^{4}$ Grupos de notas empregadas com valores alterados do que normalmente representam.
} 
adentrar na compreensão de como tais categorias se cristalizam na estrutura da música, daí sua relação com os fenômenos sociais e históricos. (ADORNO, 2011, p. 14).

Segundo o filósofo, fenômenos como o da Indústria Cultural ${ }^{5}$

tem educado suas vítimas para evitar-lhes todo esforço no tempo livre que destinam ao consumo dos bens espirituais que lhes fornece, elas se aferram com tenacidade ainda maior à aparência que apaga a essência [...] tornam tão obtusa a capacidade perceptiva que a concentração de uma audição responsável é impossível" (ADORNO, 2011, p. 18).

A partir dessas considerações percebemos que o direcionamento das reflexões propostas por Adorno na Filosofia da nova música, vai muito além de meras considerações sobre o gosto e discussões sobre estilos musicais ou referências nacionalistas biográficas. Somente a análise filosófica sobre a nova música que leve em conta a situação do processo histórico da arte musical na sua essência, por meio de um procedimento estético que considere o fator sociológico, pode levar ao que o filósofo denominou progresso, ou seja, à capacidade estética de audição musical cognitiva que, por sua vez, é capaz de reverter a lógica de mercado que esvazia o sentido da arte, em nosso caso especificamente, a musical.

A seguir apresentamos, brevemente, como Adorno compartilha essas reflexões ao analisar os dois compositores escolhidos por ele: Igor Stravinsky e Arnold Schoenberg.

\section{Sobre a ideia de regressão em Stravinsky}

Igor Stravinsky (1882-1971) compositor russo (que passou maior parte de sua vida na França, Suíça e Estados Unidos, recebeu naturalização francesa em 1934 e americana em 1945). Seu talento foi reconhecido pelas composições de obras musicais coreografadas, nas quais o compositor mostra todo seu poder criativo, sua variedade de estilos e suas referências estéticas.

De acordo com Adorno, em Stravinsky encontramos um chamado à regressão de nossa audição, mesmo o compositor tendo desenvolvido sua produção musical no contexto da chamada música erudita ou clássica. O processo de regressão foi evidenciado pelo filósofo a

\footnotetext{
${ }^{5}$ Indústria Cultural é um termo cunhado por Adorno e Horkheimer na obra Dialética do Esclarecimento, na qual o filósofo procura demonstrar a situação da produção artística no contexto de uma sociedade capitalista e industrial. O termo visa demonstrar que o processo de instrumentalização da técnica fomenta um fenômeno social que alimenta o sistema capitalista atingindo as massas por meio de uma consciência consumidora de bens culturais. Para Adorno com a Indústria Cultural a arte deixa de ser autônoma por seu conteúdo reflexivo sobre sua própria existência e a vida do homem, para ser produzida em atendimento ao mercado consumidor. (ADORNO, 1985, P 57-80).
} 
partir da análise que o mesmo teceu sobre as obras: Petruschka, Sagração da primavera e A história do Soldado, das quais o crítico frankfurtiano extraiu elementos que permitiram comprovar a presença de certo retrocesso, tematizado de restauração, que posiciona o compositor russo no polo da regressão, oposto ao de Schoenberg que é posicionado no polo do progresso.

Adorno afirma que há certas características nas obras de Stravinsky que dão sustentação à sua crítica em prol do caráter regressivo presente nas obras do compositor russo. Entre estas marcas convém ressaltar: a busca por autenticidade; o objetivismo em prol do subjetivismo; a utilização do sistema tonal; a presença de elementos lúdicos infantis; certo grau de romantismo nostálgico; certa dosagem de esquizofrenia, narcisismo e sadomasoquismo; repulsão da expressão; ausência de discussão dialética com a história da música e outras que tentaremos discorrer para dar suporte aos objetivos desta pesquisa.

A busca pela autenticidade é o caminho, em Stravinsky, pelo qual passam os demais elementos que conduzem à regressão. O compositor russo busca por uma originalidade que o posicione como um clássico eternizado, dotado de validade própria e não simplesmente um moderno repleto de tendências pautadas na efemeridade (ADORNO, 2011, p. 110). Para o compositor sua autenticidade deve estar estruturada primeiramente no objetivismo musical, objetivismo isento de quaisquer influências subjetivistas, como compreende Adorno. Segundo o qual

Em Stravinsky, a subjetividade assume o aspecto de vítima, mas - e aqui ele zomba da tradição da arte humanista - a música não se identifica com ela, mas com sua instância destruidora. Em virtude da liquidação da vítima, a música se priva de intenções e, portanto, de sua própria subjetividade" (ADORNO, 2011, p. 114).

O esforço pela autenticidade pautada numa positivação da objetividade é empobrecedora, reducionista e contraditória. Além disso, o próprio Stravinsky se apoia em uma objetividade determinada por sua própria subjetividade. Uma subjetividade autoritária imposta por meio da restauração de formas musicais atemporais, descontextualizadas de sua época e discursada sobre um sistema tonal reificado. Paul Griffiths em A música moderna (1998) transcreveu um trecho da autobiografia da vida de Stravinsky (1935) no seguinte teor:

Considero a música, por sua própria natureza, essencialmente incapaz de expressar o que quer que seja, sentimentos, atitudes mentais, estados psicológicos, fenômenos da natureza, etc. [...]. O fenômeno musical nos é dado com a única finalidade de estabelecer uma ordem nas coisas, inclusive 
e sobretudo na coordenação entre o homem e o tempo (GRIFFITHS, 1998, p. 62).

Nesta citação observa-se o impulso de objetividade dado pelo compositor, que para Adorno não se efetiva, mesmo porque não há como retirar a subjetividade da relação que o ser humano estabelece com um objeto determinado, qualquer objetividade passa pelas faculdades e crivos da percepção que, por si, já é a configuração de uma subjetividade.

Stravinsky, também, não satisfaz seu impulso de objetividade porque seu resultado sonoro traz consigo uma origem romântica que por sua vez nos remete às produções wagnerianas e straussianas, principalmente quando a orquestra está no seu tutti ${ }^{6}$ configurando uma massa sonora luxuriante (ADORNO, 2011, p. 126). A utilização de instrumentos musicais exóticos já esquecidos também corrobora para certa dosagem de um romantismo nostálgico dos tempos arcaicos. Assim, sua intenção anti-subjetivista não satisfaz seu impulso objetivo e sua produção musical se torna um trabalho frustrado e ideológico, impulsionado pela força do desejo de tornar sua música eternizada, já que, nas palavras de Adorno.

A negação do elemento negativo subjetivo próprio desta atitude autoritária, a negação do próprio espírito, a própria essência da negação que seduz por sua hostilidade a toda ideologia, tudo isso se estabelece como uma nova ideologia. (ADORNO, 2011, p. 154).

O sistema tonal é mais um dos elementos empregado por Stravinsky na caminhada rumo à autenticidade instigadora do caráter de regressão identificado por Adorno na obra do compositor. Todo seu esforço pela autenticidade se estrutura no uso da tonalidade e o tonalismo é um meio de enquadramento da linguagem musical aos rigores de uma dimensão técnica que se sujeita às formas, estilos, tensões e repouso, harmonias e melodias presentes na música, principalmente, burguesa. Logo, consiste no caminho fácil desdenhado pelo compositor russo que o conduz à autenticidade, tendo em vista que é nesta empreitada que o ele encontra a credibilidade do público.

Nessa perspectiva, o compositor contribui para a demolição de todas as intenções de continuidade exigidas pelo curso natural da história da música. Há uma quebra das mediações históricas e um reforço para um falso mediatismo que fornece à sua obra um aspecto de mercadoria fetichizada, capaz de encobrir toda subjetividade mediada pelo curso da história. Stravinsky busca pelo arcaico de maneira descontextualizada e fragmentada, nega-se a construir o novo, por isso se volta ao primitivismo à maneira que contribui para enganar o

\footnotetext{
${ }^{6}$ Momento da execução musical em que todos os executantes devem tocar ou cantar simultaneamente.
} 
ouvinte com uma falsa mediação. Na verdade, essa forma encontrada por Stravinsky acaba reforçando a imediaticidade, assim como ocorre com o procedimento fetichista desenvolvido no contexto do sistema capitalista.

A busca pelo arcaico é outro fator que fortalece a visão crítica adorniana a respeito da regressão stravinskiana. "A música de Stravinky é um fenômeno marginal, apesar da difusão de seu estilo, que alcança quase toda a geração jovem, porque evita discussão dialética com o decurso musical no tempo, discussão que representa a essência de toda a grande música, desde Bach" (ADORNO, 2011, p. 144).

Assim, a incumbência de Stravinsky está sedimentada na sua abstenção em trabalhar com os elementos musicais estruturados por problemas atuais. Fato que dissimula a capacidade de shock na sua música que se presta a absorção e reprodução condicionadas à aniquilação da reflexão pelo indivíduo sobre sua própria condição que é determinada pelo mundo administrado.

Diante do exposto, percebemos como Adorno constrói suas reflexões para demonstrar a estética restauradora em Stravinsky e progressista em Schoenberg. O filósofo atesta que o compositor russo se apoia numa autenticidade marcada por um objetivismo musical sustentado nas premissas do sistema tonal gerador de uma falsa mediaticidade que promove a debilidade da capacidade de audição por parte do público e impede a compreensão crítica do contexto histórico presente no curso do desenvolvimento da própria música.

Desta forma, surge semelhança da música de Stravinsky com os produtos da indústria cultural, ou seja, ambos promovem a alienação do indivíduo diante da realidade. Consequentemente há uma perda da sensibilidade reflexiva para dar azo ao embrutecimento do espírito que se sustenta a partir de um ser humano oprimido e reificado.

A seriedade desta regressão não está exclusivamente pautada na tentativa de positivação da objetivação técnica estrutural das composições de Stravinsky, porém, está mais ainda, no poder que o resultado final do efeito sonoro de sua música sugere ao sistema psíquico, do qual observamos um processo degenerativo e de desuso da consciência, já que o indivíduo passa agir pelos impulsos do inconsciente. Algo análogo ao sistema econômico administrado nos moldes do capitalismo, o qual mantém o foco no inconsciente da massa e se fortalece pela perpetuação de indivíduos alienados à missão do consumo.

A seguir, tentaremos identificar este procedimento regressivo e alienante a partir das considerações que Adorno traz sobre algumas produções de Stravinky: 
Petruschka (1910/11), trata-se de um balé com cenas burlescas composto em quatro quadros. O balé narra um conto popular russo sobre a história de um fantoche de rua. Num dia festivo e diante de um público de rua, um mágico apresentador de teatros de marionetes faz uma apresentação com três bonecos mágicos: Petruschka, um mouro e uma bailarina. Uma mágica confere sentimentos humanos aos bonecos que começam a dançar, nasce, assim, um triangulo amoroso entre os bonecos que termina com o assassinato de Petruschka.

Todo este desfecho ocorre juntamente com um material sonoro musical inspirado no folclore russo. Stravinsky utiliza-se de uma música diatônica ${ }^{7}$ para representar o humano e do cromatismo $^{8}$ para representar os bonecos. A grande marca desta produção musical está no uso da bitonalidade 9 .

Adorno vislumbra em Petruschka a presença do afastamento da subjetividade. O caráter trágico do clown profetiza a fraqueza da subjetividade que, mesmo aparente, é manifestada ironicamente (ADORNO, 2011, p. 114).

A presença do grotesco é a marca característica de Petruschka, "quando se encontra um elemento subjetivo se o encontra depravado, sentimentalmente falso ou idiotizado. É invocado como algo já mecânico, reificado e de certa maneira morto" (ADORNO, 2011, p.115). A obra é "estilisticamente "neoimpressionista'10, compõe-se de inumeráveis peças de arte, desde a desordenada confusão de vozes da praça do mercado até a imitação exagerada de toda a música que repele a cultura oficial" (ADORNO, 2011, p.113). Uma obra carregada do humor burguês.

A presença de elementos lúdicos da infância é outro fator que merece destaque nesta empreitada de evidenciação da regressão em Stravinky feita por Adorno. "O impulso fundamental de Stravinsky visando dominar a regressão com um procedimento disciplinado determina mais que nenhum outro a fase infantil" (ADORNO, 2011, p. 131). A ligação da música de Stravinsky com a dança faz brotar na sua obra a relação do som com o movimento corpóreo. A liberdade de movimentos remete aos movimentos desengonçados de uma criança dançando livremente, mais parecidos com comportamentos esquizofrênicos. Há, ainda, os contos por trás das performances bem como as personagens cômicas (bonecos, clown,

\footnotetext{
${ }^{7}$ Música composta a partir da escala diatônica, a relação intervalar dos sons são dispostos por tons e semitons.

${ }^{8}$ Música composta a partir da escala cromática, a relação intervalar dos sons são dispostos apenas por intervalos de semitons.

${ }^{9}$ Música composta em duas tonalidades ao mesmo tempo.

${ }^{10}$ Estilo, técnica de uso de cores fortes e brilhantes e de pequenos pontos ou Pontilhismo que configuram um objeto, tipo PIXELS de hoje. Mais tarde, o fauvismo recupera esse tipo de cor, forte e brilhante. O termo aqui é empregado no sentido de demonstrar uma produção musical forte, densa, impactante e contrastante.
} 
mágico) remissivas à imaginação infantil, tudo isso sugere um meio de alienação mental para tornar manifesto um meio de atualização do mundo primitivo, o processo de regressão à infância.

A paródia, isto é, a forma fundamental da música ao quadrado, significa imitar algo e, imitando-o, ridicularizá-lo. Semelhante atitude, que a princípio parece suspeita aos burgueses, por considera-la própria do músico intelectual, se adapta facilmente à regressão. Assim como uma criança desmonta um brinquedo e logo o reconstrói defeituosamente, do mesmo modo se comporta a música infantilista com os modelos (ADORNO, 2011, p. 143).

A obra se apresenta de modo a levar o indivíduo a não sentir necessidade de criticidade ao que lhe é inconscientemente apresentado: um processo de reificação representado pelo estereótipo da desumanização, por meio da estratégia de fácil digestão aos moldes do preconizado no contexto da Indústria Cultural.

A Sagração da Primavera (1913) é a representação de um grande ritual sagrado e pagão. Sábios anciões estão sentados em círculo para observar a dança da morte de uma virgem que é oferecida em sacrifício aos deuses da primavera. Uma série de danças ritualísticas é desencadeada em prol do sacrifício final da virgem que é condenada a dançar até a morte.

O balé se desenvolve sob o poder de uma música com inconsistência formal composta por meio de uma grande diversidade rítmica, cromatismos, harmonizações ríspidas, superposições de melodias, de acordes e de tonalidades, grandes associações timbrísticas de efeitos violentos e uma pulsação vigorosa. Estes são alguns dos elementos essenciais utilizados por Stravinsky para representar rudimentos do folclore russo aliados ao primitivismo ritualístico, sagrado, ao arcaico que se refere ao sacrifício humano.

A estreia desta obra chocou o público, mas não impediu de torná-la uma referência no universo musical. A sagração da primavera "já tem resistido a quase meio século como símbolo musical da nossa época, caracterizada pelo intelectualismo a serviço da barbárie" (CARPEAUX, 2001, p. 420). A obra abalou a estrutura de importantes características da música, tais como aspectos harmônicos, timbres, formas, estruturação orquestral, as dissonâncias, valorização do percussivo ao melódico. A primeira apresentação desta obra escandalizou a sociedade francesa da época, gerou caos na plateia, muitos se retiraram do teatro no meio do espetáculo. Ainda nos dias atuais a obra mantém sua natureza provocativa e 
subversiva o que causa certa estranheza aos ouvidos menos familiarizados com o universo musical.

As reflexões de Adorno sobre a Sagração da primavera seguiram a mesma linha de raciocínio que o filósofo empregou para traçar sua crítica à Petruschka. O filósofo observou e criticou a presença de uma banalização do passado; a utilização do sacrifício como destino final humano; o enfraquecimento da expressividade; a presença de um shock condicionado.

O sacrifício carregado de humor que foi apresentado em Petruschka foi, também, retomado na Sagração e pontuado por Adorno como um "sacrifício sem tragédia, praticado não à imagem nascente do homem, mas à cega confirmação de uma condição que a própria vítima reconhece, ora com o escarnio de si mesma ora com a própria extinção" (ADORNO, 2011, p. 116). Este motivo determinou o desenvolvimento da música que veio para fortalecer, ainda mais, a temática do sacrifício sadomasoquista que atinge aspectos da vida social ao camuflar uma realidade regressiva, alienante irreflexiva.

O sacrifício humano, em que se anuncia a crescente potência do coletivo, é determinado pela insuficiência da própria condição individual e precisamente a selvagem representação do selvagem não satisfaz simplesmente, como lhe censura o filisteu, mas também o desejo de sufocar a aparência social, o impulso para a verdade sob mediações e mascaramentos burgueses da violência" (Idem, 2011, p. 117).

O sacrifício final da vítima é apresentado na obra com certa frieza e como sendo algo já esperado passivamente. Esse dado traz certa dosagem de apologia à passividade do sujeito diante de seu inevitável fim social, determinado pelas relações econômicas e imposto por um sistema capitalista opressor. Isso nos remete ao caráter sadomasoquista da obra na qual a vítima se entregou ao sacrifício sabendo de sua morte, da mesma maneira que o indivíduo se entrega às determinações sociais do mundo regido pelo vigor do sistema do lucro, do consumo e da alienação.

A força do coletivo surge deste contexto, tendo em vista que o ouvinte sempre se apoia na intenção da tribo e nunca parte em defesa da virgem sacrificada. Assim, o ouvinte se identifica com o coletivo e renuncia sua própria individualidade por meio de uma cumplicidade masoquista, porque inconscientemente se vê na condição da vítima.

Para dar suporte a todos esses elementos presentes na Sagração, o aparato musical foi produzido ora a partir de partículas melódicas diatônicas, representando o folclore russo, ora a partir da escala cromática, porém nunca se apresentou por uma escala preordenada; há grande exploração da variante rítmica com acentuações modificadas; surgem diferenças temáticas; 
contradições entre o desenvolvimento vertical e o desenvolvimento horizontal; exploração da politonalidade; dissonâncias; polifonias; ostinatos ${ }^{11}$; certas dosagens de contraponto e uma variedade de timbres instrumental.

A orquestra é utilizada pelo compositor como sendo um único instrumento de percussão, na qual a constância rítmica de caráter primitivo, de irregularidades métricas e acentuações deslocadas, sobrepõe a estrutura harmônica e melódica da obra, o que garante o quadro de inconsistência formal da obra e produz um shock condicionado, condicionado à repetição do ritmo e não à intensidade sonora.

Adorno esclarece que o conceito de shock é oriundo desta época e "pertence ao estrato fundamental de toda a nova música" (ADORNO, 2011, p. 122) sua causa social pode ser identificada pela disparidade das forças presentes no desenvolvimento civilizatório técnico de um lado, e na estrutura corpóreo/psíquica humana de outro lado. Neste contexto,

Pelos shocks, o indivíduo percebe diretamente sua nulidade frente a gigantesca máquina de todo o sistema. Desde o século XIX os shocks deixaram atrás de si seus vestígios nas obras de artes, e, do ponto de vista musical, Berlioz foi talvez o primeiro para cuja obra os shocks eram essenciais. Mas tudo depende de como a música realiza a vivência do shock (ADORNO, 2011, p. 123).

Assim, o shock seria a representação da fraqueza humana diante das estrondosas forças exteriores impostas ao sistema psíquico gerando um quadro de angústia que é passado pelo filtro da história até o resgate da assimilação de uma circunstância traumática (ADORNO, 2011, ps. 121-123).

Na Sagração da primavera, segundo Adorno, o shock é apresentado pela repetição rítmica e não pela intensidade rítmica, num "contínuo apresentar-se em que a irregularidade do retorno substitui o novo" (ADORNO, 2011, p. 122). Assim, a utilização de elementos descontextualizados, fragmentados aliados ao ostinato rítmico constante, impede o ouvinte de um registro histórico na direção de um shock que toque as profundezas da sensibilidade como deveria ser.

Em Stravinsky não existe nenhuma disposição angustiosa nem um eu que lhe oponha resistência, mas dá-se por aceito que os shocks não permitem que se aposse deles. O sujeito musical renuncia a impor-se e [...] comporta-se literalmente como um ferido grave, vítima de um acidente de que não pode recuperar-se e que por isso repete continuamente os esforços desesperados dos sonhos. O que parece absorção completa dos shocks, ou seja, acomodação da música aos golpes rítmicos provenientes do exterior, é, na

\footnotetext{
${ }^{11}$ Um motivo, uma frase, um ritmo ou uma melodia que se repete continua e persistentemente.
} 
verdade, justamente um testemunho de que a absorção fracassou" (ADORNO, 2011, p.123).

Desta forma, o sentido musical em Stravinsky dificulta a configuração do shock que toque os recônditos da alma por um processo de sensibilização sedimentada pela expressão humana, sem que o indivíduo se perca no esvaziamento de sua própria condição. Antes apresenta um shock condicionado e direcionado à absorção pelo indivíduo de sua situação angustiante imposta pelo mundo administrado.

Felício Ramalho Ribeiro em pesquisa intitulada Regressão auditiva: o impedimento da música como conhecimento em Theodor Adorno, sustenta que

na Sagração da primavera o sacrifício incontingente do indivíduo frente às opressivas forças coletivas e econômicas, como a conseguinte obliteração dos antagonismos sociais, é disposto pela inocuidade dos movimentos melódicos - condizentes ao indivíduo - frente à sua determinação pela estrutura rítmica e harmônica. Além disso, uma enganosa proposta de liberação do libidinal arcaico é promovida pela ênfase excessiva do ritmo, que, enquanto elemento essencial e exclusivo de articulação da intimidade corpórea, já perdeu sua validade no tempo (RIBEIRO, 2009, p.144).

A citação acima condensa as reflexões críticas elaboradas por Adorno à Sagração da primavera. Apontando, inclusive, a relação da obra com os fenômenos sociais que permeiam a vida humana, contribuindo para a adaptação do sujeito às condições econômico-ideológicas vigentes.

Já A História do Soldado (1918) é uma obra inspirada num conto popular russo, conta a história de um soldado que volta da guerra e no caminho de regresso para sua casa encontra com o Diabo disfarçado de pessoa que tenta apoderar-se de sua alma, representada por um violino. O soldado concorda em dar seu violino (alma) em troca de um livro que prevê o futuro e lhe confere riqueza. Após três dias, o soldado retorna para sua casa, mas sua mãe e sua noiva não mais o reconhece, porque na verdade se passaram três anos.

Desesperado, o soldado tenta reaver seu violino (sua alma) com o diabo, mas não consegue. Vai, então, até o palácio de um rei e descobre que o mesmo estava oferecendo a mão de sua filha para quem o curasse de uma doença. O soldado tenta a sorte com o diabo, e num jogo de cartas consegue embriagar o diabo e resgatar seu violino. Em posse do instrumento o soldado toca para o rei que é curado e em troca o soldado se casa com a princesa. O Diabo volta para buscar o violino, mas toda vez que se apresenta o soldado toca e ele dança até a exaustão. Um belo dia, quando o soldado e a princesa vão até a antiga aldeia 
do soldado, o diabo aparece e leva com ele o príncipe, termina a obra com a vitória do diabo sobre a alma do soldado.

Uma obra seca, espirituosa que traz uma paródia ao militarismo e ao mercantilismo por meio de uma sonoridade melódica ríspida, certa aridez instrumental e um amparo rítmico próprio para criar o clima da peça. Obra moderna, em que a música é produzida por frases não resolvidas ou resolvidas fora do tempo que, por vezes, nos remete ao elemento irônico e sarcástico da música.

A Histoire du soldat, com um tratamento coerente, faz nascer dos restos da linguagem musical despojada outra linguagem fantasticamente agressiva. Poderia ser comparada com as montagens oníricas dos surrealistas, construídas com resíduos da vida cotidiana [...]. No intento de chegar a tal linguagem, Stravisnky se toca com Joyce: em nenhum outro momento está mais perto de sua mais íntima aspiração, isto é, de construir o que Benjamim chamou história primitiva do moderno (ADORNO, 2011, p. 141).

Nota-se nesta obra, uma representação típica do sistema mercantilista e fetichizante do lucro, a alienação do indivíduo devido ao encantamento desencadeado pelos produtos oferecidos pelo sistema econômico consumista, bem como as trágicas consequências de se deixar seduzir acriticamente e passivamente ao consumo, às artimanhas da enganação e do embrutecimento dos sentidos e a consequente perca da essência humana.

RIBEIRO (2009) compreende a crítica de Adorno direcionada à História do soldado como "o índice de sanidade mental, o transtorno mental e efetivo do sujeito no capitalismo tardio é apresentado por meio de uma abusiva justaposição de formas desgastadas, desconexas entre si, e, portanto, insuficientes para a construção de um sentido musical" (RIBEIRO, 2009, p. 144).

É nesta obra de Stravinsky que podemos melhor visualizar a presença do quadro de esquizofrenia como elemento caracterizador de distúrbios psicológicos e ensejador do aspecto regressivo da obra (ADORNO, 2011, p. 135). A história do soldado faz uso da proposta de composição conhecida como música ao quadrado, que se configura na forma de paródia, e põe em evidencia o infantilismo da obra. Um modelo de música que se estrutura em temas e ritmos populares, em melodias interrompidas e um frequente quadro de combinações timbrísticas.

A obra é representada por intervalos entre dança, narração e música e a instrumentação reduzida sugere um grupo de câmara pequeno. A música apresenta ritmos populares como o tango, ragtime, valsa, a marcha e outros. 
Diante do exposto, por meio da análise crítica e filosófica construída por Adorno, observamos que Stravinsky é apresentado como um reacionário pela maneira como apresenta sua música. No entanto, vislumbramos reflexões estéticas que permitem articular sua produção musical aos elementos históricos e sociais e, a partir de então, compreendermos o sentido com que Adorno concebe a regressão: em Petruschka podemos visualizar a crítica que o filósofo teceu sobre o processo de satirização do sujeito e certa banalização da condição humana diante de uma sociedade administrada; em a sagração da primavera Adorno propõe refletirmos sobre o sacrifício do indivíduo diante das opressões do modelo econômico gestado pelo sistema capitalista. Bem como o resgate libidinoso do arcaico que já não tem mais validade no mundo atual; em A história do Soldado não há como negar o sintoma de sanidade mental e afetiva do indivíduo mercantilista inserido no mesmo sistema capitalista.

Após a constatação, em Adorno, do efeito degenerativo direcionado à capacidade de escuta musical que o sistema composicional de Stravisnky causa no indivíduo, convém analisarmos a outra faceta do método (dialético) de reflexão adotado pelo filósofo na figura de Shoenberg.

\section{O progresso como fundamento estético em Schoenberg}

Arnold Schoenberg (1874-1951) compositor austríaco dotado de grande erudição musical, sua carreira composicional foi determinada pela sua audácia em relação à harmonia, às dissonâncias e ao cromatismo. Foi catedrático no conservatório de Berlim desde 1925. Em 1933 foi obrigado pelos nazistas a emigrar para os Estados Unidos, onde morreu na cidade de Los Angeles no dia 13 de julho de 1951.

É em Schoenberg que Adorno vislumbrou uma produção artística musical capaz de impor um estorvo à restauração regressiva apresentada por Stravinsky e motivar o progresso musical em favorecimento do desenvolvimento cognitivo humano. A autenticidade de Schoenberg foi reconhecida por Adorno pelo fato de o compositor desempenhar, de maneira erudita e intelectual, a missão de fundador de uma nova ordem musical.

As convenções tradicionais burguesas dirigidas para o processo de produção musical cumpriram sua função num determinado tempo e lançaram indícios de tendências que anunciavam o seu próprio desmoronamento. Nem a música polifônica de Bach, nem as variações de Beethoven e as dissonâncias cromáticas de Wagner conseguiram esgotar o 
conteúdo de verdade do fenômeno musical. Fato que, também, comprova a ausência de esgotamento das constantes mudanças e transformações pelas quais a música está permanentemente envolvida. Aliás, a vida musical não é, e nem pode ser paralisada, principalmente quando relacionada com a sociedade que está constantemente em meios de crises econômicas, políticas e culturais.

Schoenberg propôs um modelo musical que considera a música em si, a partir de seus fenômenos sonoros. Contudo, não abandonou a linha de evolução da história da música, ao contrário, o compositor sugere uma produção musical contextualizada com sua época sem abrir mão de materiais de outros momentos históricos, a exemplo da polifonia de Bach; da série de Beethoven e do cromatismo de Wagner. Desta forma, "a tradição e o novo começo se entrecruzam em Schoenberg, assim como o aspecto revolucionário e o conservador" (ADORNO, 1998, p. 148), e o resultado final é o progresso.

A grande proeza está no fato de que a música de Schoenberg explora os elementos musicais de um modo que nunca foram explorados ao longo da história da música. Adorno destaca que a maneira com que Schoenberg trabalha as dissonâncias, os cromatismos, a polifonia, a série e as variações é agregada ao contexto histórico e social, e evidencia os momentos recalcados e não realizados durante o desenvolvimento de nossa civilização, o que também fortaleceu a Schoenberg a autoria de fomentador da música do progresso.

É das sonoridades existentes e dispostas ao compositor que se extraem os materiais musicais. Estes materiais são reduzidos ou ampliados no curso da história, portanto, são característicos e resultantes do próprio processo histórico. Assim, embora os meios de manifestação desses materiais sonoros não sejam apresentados em sua origem, o processo de mediação histórica está envolvido em todo o material musical. Importante destacar a afirmação de Adorno para o fato de que nem tudo é possível em todos os tempos e, assim, não podemos afirmar que "o acorde perfeito é a condição necessária e universalmente válida de toda a concepção musical possível e que, portanto, a música deve ater-se a ele [...] esta não é outra coisa senão uma superestrutura útil para tendências de composições reacionárias" (ADORNO, 2011.p. 36).

Além disso, na obra Prismas (1998) Adorno dedica uma seção à Schoenberg, na qual salienta características que corroboram com o poder da música do compositor austríaco para a produção do conhecimento e sua importância para a formação do músico.

De fato, a música de Schoenberg exige desde o início uma participação ativa e concentrada; a mais aguçada atenção à multiplicidade do simultâneo; a 
renúncia às muletas habituais de um ouvinte que sempre sabe o que vai acontecer; uma atenta percepção do único e do específico; e a capacidade de aprender com precisão caracteres que muitas vezes se modificam no menor espaço de tempo, e também a história desses caracteres, desprovida de qualquer repetição (ADORNO, 1998, p. 146).

A partir dessas considerações percebemos a força cognoscível da produção musical de Schoenberg e a importância de sua presença na formação musical, principalmente sob a ótica crítica e reflexiva impetrada por Adorno, a contar do expressionismo ${ }^{12}$, atonalismo ${ }^{13}$ e do dodecafonismo $^{14}$.

Adorno sugere atentarmos para o fato de que a compreensão das dissonâncias schoenbergianas demanda do sujeito (compositor e ouvinte) maior envolvimento com a música, exigência que é determinada pelos próprios materiais musicais, já que estes são representações dos fenômenos sociais envoltos tanto no sujeito quanto no objeto.

Por isso a discussão do compositor com o material é também discussão com a sociedade, justamente na medida em que esta emigrou para a obra e já não está à frente da produção artística como um fator meramente exterior, heterônomo, isto é, como consumidor ou rival da produção. As advertências, que o material transmite ao compositor e que este transforma enquanto as obedece, constituem-se numa interação imanente (ADORNO, 2011, p. 36).

\footnotetext{
${ }^{12} \mathrm{O}$ Expressionismo é um termo tem sua origem nas artes plásticas, no entanto, adentrou o universo artístico musical no qual traz em seu entendimento uma extrema intensidade de expressão dos sentimentos internos humanos, que se agregam a certa necessidade de demonstração de rebeldia e inovação. É fruto do romantismo tardio em que os compositores passaram a desejar uma música que pudesse expressar toda sua carga de emoções mais profundas e intensas. O expressionismo prega a inexistência de leis externas (formas, regras de composição) para fazer valer uma obediência à voz interior. "O campo temático do expressionismo é o homem do mundo moderno, tal como o descreve a psicologia do início do século XX: isolado, joguete impotente de forças que não compreende, presa de conflitos interiores, tensões, ansiedade, medo e de todos os impulsos profundos e irracionais do subconsciente, em revolta aberta contra a ordem estabelecida e as formas aceites". (PALISCA, 1994, p. 732)

${ }^{13}$ Assim, o atonalismo é uma expressão comumente empregada para apontar o modelo de produção musical que não está baseado em relações harmônicas e melódicas fixadas num centro tonal. Indica a música elaborada fora das regras do tonalismo. O Atonalismo emerge do esgotamento do sistema tonal que a partir do início do século XX levaram compositores buscar maneiras de produzir música que estivessem fora das regras do sistema em vigor. Certas tendências empreitadas a partir do romantismo, como o uso de acordes dissonantes cromáticos, a busca por novos timbres e atmosferas sonoras, bem como as ousadas modulações (principalmente em Wagner, Debussy e Havel) passou levar o ouvinte à incerteza da tonalidade na qual a música havia sido construída. Daí os indícios que levaram à atonalidade que foi empregada fortemente por compositores expressionistas.

${ }^{14} \mathrm{~A}$ ausência de regras no contexto do atonalismo levou Schoenberg a criar e organizar um método de composição que considerasse as 12 notas da escala cromática, na qual estão presentes os doze sons conhecidos no universo da música ocidental - o Serialismo dodecafônico. No serialismo dodecafônico "a base de cada composição é uma sequência ou série das doze notas que integram a oitava, dispostas pela ordem que o compositor determinar" (PALISCA, 1994, p. 733).
} 
As condições sociais, por não apresentarem nada obrigatório e autêntico, favorecem que o movimento dialético musical vá contra a obra fechada, na qual todo procedimento que foge das regras do sistema onipresente são excluídos. Fator de resistência à nova música.

Convém destacar que as convenções da produção musical tradicional não proíbem o compositor de explorar outras sonoridades necessárias para um determinado momento. Além disso, as diferentes dimensões da música - melodia, harmonia, ritmo, forma, contraponto, instrumentação - foram desenvolvidas de maneiras independentes ao longo da história, foi assim com o contraponto em Bach e com os cromatismos dissonantes de Wagner.

Na música de Schoenberg não só estão igualmente desenvolvidas todas as dimensões, mas todas elas se produzem de maneira tão separada que converge (ADORNO, 2011, p. 50). A liberdade da expressão na produção musical faz desaparecer as diferenças existentes entre o essencial e o acidental; o tema e o desenvolvimento; a tensão e o relaxamento; o centro e as marginalidades. A partir de então, o princípio do contraste da justaposição de um tema (modelo) confere o mesmo nível de importância a todos os materiais musicais.

Há, também, que o parâmetro de tempo, que é o sintoma mais evidente de uma música e a base da concepção de obras musicais desde o século XVIII, sofre certa alteração. O critério de tempo em Schoenberg apresenta uma nova maneira de conceber a expressividade que "não se trata de paixões simuladas, mas antes de movimentos corporais do inconsciente, de shocks, de traumas, que ficam registrados no meio da música” (ADORNO, 2011, p. 40). Sua música pode ser vista como um jogo com as convenções de onde a liberdade deve ser aflorada. Sendo assim, sua música tende ao conhecimento.

A arte que se articula na direção do progresso é aquela que aponta níveis de valoração ao processo de produção do conhecimento. Adorno atenta para o fato de que uma obra de arte verdadeira é articulada, estruturalmente, a partir do vínculo que esta estabelece com os problemas sociais de sua época. Assim, o elemento histórico é apontado como essencial para o procedimento de uma produção artística favorecedora do processo de produção do conhecimento (ADORNO, 2011, p. 35-38).

Essas considerações apontadas por Adorno mudam o rumo da estética tradicional para favorecer o afloramento de reflexões em torno da arte (música) a partir de sua conexão com a sociedade. De maneira tal, que uma apreciação musical exige a compreensão de todo processo de produção do conhecimento em volta da criação artística. 


\section{Considerações finais}

O problema que norteou essa investigação foi definido pela questão: Quais os valores estéticos são apontados por Adorno para eleger Schoenberg como representante da filosofia da nova música?

Visando apresentar algumas considerações sobre esse problema e também para os objetivos específicos definidos, a partir das análises e das deduções feitas apresentamos nesta seção alguns achados que poderão contribuir para o esclarecimento da temática proposta.

Se considerarmos que na concepção estética tradicional e especialmente na arte burguesa o belo, o sensível e a arte estão vinculados com a finalidade de agradar ao público, um público para o qual cabe a tarefa de julgamento da arte a partir do seu gosto, por meio de uma espécie de sexto sentido responsável pela manifestação da beleza artística e definição do que seja o belo. Essa denotação caminhou até o momento em que a produção artística passou a ser regida sob a égide do mercado e da Indústria Cultural, como bem observou Adorno.

É neste contexto que o crítico frankfurtiano concebeu uma nova maneira de compreender a estética que difere da tradicional resposta à pergunta: $O$ que é o belo? A estética em Adorno sugere uma compreensão filosófica a respeito da arte a partir de sua coesão com a sociedade, com isso, a estética deixa de ser tratada como ponto marginal da filosofia integrando-se a ela como uma essência social merecedora de reflexões filosóficas. Segundo Alex Thomson

A estética é frequentemente considerada um aspecto um tanto marginal da filosofia, e nossas ideias sobre beleza uma mera curiosidade para a investigação psicológica; portanto, pode ser difícil entender como ela se torna central para a descrição da sociedade e da história por Adorno [...] crucialmente para Adorno, a experiência da estética não é conceitual, isto é, ela não é inteiramente receptiva à expressão racional e, portanto, filosófica (THOMSON, 2010, p. 73 e 75).

Desde o início do século XX, Adorno lançou seu olhar para a nova música, movimento do qual emergiu suas reflexões condensadas na obra Filosofia da nova música na qual o filósofo se valeu da produção musical de Stravinsky e Schoenberg e propôs, a partir de então, uma concepção estética vanguardista, uma estética voltada para a ordem das dissonâncias.

Da mesma forma com que a nova música se volta para novas experiências sonoras, a estética adorniana se volta para uma nova experiência teórica sobre a obra de arte que deve 
ser produzida ou apreciada sob a ótica histórica e social, a fim de resistir às regras do jogo do valor de troca e se impor como fenômeno dotado de poder enigmático do qual emerge o desejo pelo novo, pela liberdade, pelo conhecimento e pelo esclarecimento.

Embora o filósofo refira-se mais à obra de arte do que à Arte propriamente dita, ele acredita e se posiciona dialeticamente entre a objetividade e subjetividade da arte, fato que fortalece ainda mais sua experiência estética como expressão racional, social e, portanto, filosófica.

As considerações de Adorno sobre a obra de arte vão além do simples entendimento de forma e conteúdo, o filósofo acredita na força da negociação com as formas precedentes e com o contexto social atual, bem como no elemento temporal como marca característica da Arte que nunca é acabada, mas sempre transformada.

Desta forma, o filósofo está mais interessado na arte que não integra o processo de mercadoria, ou aquela arte cuja integração seja mais difícil de ocorrer. Uma arte que confronta sua relação com a tradição e se liberta das convenções preestabelecidas para possibilitar um processo criativo, emancipador e, portanto, cognitivo. É desta forma que ele se aproxima mais das teorias freudianas e marxistas e menos dos conceitos de moderno, estilos, formas e vanguarda, ainda que recorra a dois artistas vanguardistas.

Alex Thomson sustenta que em Adorno "a ideia de vanguarda podia servir para identificar os modernistas que realmente conseguiram romper com o romantismo ao distinguir no modernismo as tendências que continuam a tradição estética e as que buscaram romper com ela" (THOMSON, 2010, p. 79).

No contexto musical podemos inferir que Adorno reconhece a necessidade de uma formação musical para a crítica. Assim, parece oferecer uma proposta de educação musical que não seja estruturada no ensinar pessoas a reconhecerem grandes compositores ou grandes obras da tradição burguesa, na qual impera a fixação da ideia de existência de uma grande arte e que as pessoas devem aprender a contemplá-las.

Em vez disso, o que Adorno propõe é o ensino, ou antes, a educação para o sensível no âmbito da experiência estética. Neste sentido, podemos dizer que não se ensina arte a partir de perguntas como "isto é grande arte"? Ou "gosto disso"? Mas a partir da educação para a sensibilidade, o que nos leva ao seguinte questionamento: “isto sequer é arte"? (THOMSOM, 2010, p.83). 


\section{OO DEVIR EDUCAÇÃO}

ISSN: 2526-849X

Assim, partilhamos o entendimento de que a formação humana deve ser pautada problematizações que expõem os desafios do mundo moderno, mundo este em que o ideal estético deve ser integrado ao desenvolvimento do pensamento dialético, autocrítico e emancipador.

Compartilhamos também do entendimento de que a racionalização da civilização ocidental frente aos ideais de progresso ditados pela cultura capitalista fomenta o fenômeno da regressão no âmbito da produção e da escuta musical. A obra Filosofia da nova música de Adorno, que tem suas origens no texto $O$ fetichismo na música e a regressão da audição e foi impulsionada pela Dialética do esclarecimento, que por sua vez teve suas raízes em A Obra de arte na era da sua reprodutibilidade técnica (Walter Benjamim), retrata de maneira crítica toda uma barbárie cultural configurada por um processo social que induz os indivíduos ao desenvolvimento de um ouvido regressivo em face da Nova Música.

Para caracterizar este ouvinte regressivo Adorno parte de uma análise crítica da produção musical de dois compositores que considerou extremistas: Schoenberg e Stravinsky. Adorno considera Schoenberg o polo oposto de Stravinsky, o filósofo vislumbra para o compositor austríaco o progresso, a inovação e a possibilidade de fluxo para a continuidade evolutiva da história da música. A maneira de conceber a produção musical a partir de Schoenberg favoreceu o desencadeamento de novas técnicas e vertentes composicionais, dentre as quais se destacam o dodecafonismo, o serialismo, o serialismo integral, a música espectral, a micropolifonia, a música eletroacústica e outras até, então, desconhecidos.

O filósofo frankfurtiano desenvolveu uma nova maneira de se conceber a estética que difere da tradicional. A estética, a partir do pensamento adorniano, passa retratar uma nova maneira de pensar as tensões das singularidades conceituais dos objetos artísticos que envolvem a obra de arte. Além de apontar certo nível de interesse nas questões políticas e sociais que envolvem o fenômeno artístico. Já que Adorno considera que "todas essas questões estão entrelaçadas, mas isso não porque ele busque politizar a arte, mas, antes explorar o inevitável emaranhamento de arte e política que, sempre, já foi iniciado" (THOMSON, 2010, p. 60). Assim, a experiência estética em Adorno deixa de ser meramente conceitual para ser filosófica, crítica, emancipatória.

O entendimento estético apresentado por Adorno na Filosofia da nova música vem retratar o progresso musical que se deve configurar no desenvolvimento contínuo da história da música. O filósofo amplia as tensões em torno das dissonâncias para demonstrar o 
processo de libertação da música das garras do tradicionalismo estático que acorrenta a produção musical e impede os ouvidos de aceitar o progresso musical ditado pela nova música.

Em meio as suas reflexões Adorno contribui para desmistificar a crítica negativa a respeito da nova música e demonstrar que a nova música é uma música carregada de expressividade, emoções, imprevisibilidade e traz a força do desenvolvimento cognoscível do indivíduo. O que justifica a inserção de seu pensamento no processo de formação profissionalizante em música.

Consideramos, também, que a música exerceu uma função singular no processo de constituição do pensamento filosófico de Adorno, no entanto, vale destacar que outros campos do conhecimento também alimentaram suas reflexões - o caso da psicanálise freudiana e do marxismo - e para caracterizar a dialeticidade de seu pensamento crítico, Adorno, parece não se prender a nenhum desses campos do conhecimento. Cabendo ao leitor compreender a força de sua crítica a articulá-la à realidade social a sua volta.

\section{Referências}

ADORNO, Theodor $\mathrm{W}$. O fetichismo na música e a regressão da audição. In Textos Escolhidos. São Paulo: Nova Cultura, 1996.

. Filosofia da Nova Música. São Paulo: Perspectiva, 2011.

. Prismas. São Paulo: Editora Ática, 1998.

. Teoria Estética. Lisboa: Edições 70. 1998.

CARPEAUX, Otto Maria. O livro de ouro da história da música. Rio de Janeiro: Ediouro, 2001.

GRIFFITHS, Paul. A música moderna: uma história concisa e ilustrada de Debussy a Boulez. Rio de Janeiro: Jorge Zahar Editor, S/D.

JUPIASSÚ, Hilton; MARCONDES, Danilo. Dicionário básico de filosofia. 4 ed. Rio de Janeiro: Jorge Zahar, 2006.

PALISCA, Claude V.; GROUT, Donald J. História da Música Ocidental. Portugal: Gradiva, 1994.

RIBEIRO, Felício Ramalho. Regressão auditiva: o impedimento da música como conhecimento em Theodor Adorno. 2009. Dissertação (Mestrado em Filosofia) Universidade Federal de Minas Gerais, Belo Horizonte, 2009.

SCHAEFER, Sérgio. A teoria estética em Adorno. Tese (doutorado em Letras) Universidade Federal do Rio Grande do Sul. Porto Alegre, 2012. 
THOMSON, Alex. Compreender Adorno. Tradução de Rogério Bettoni. Petrópolis, RJ: Vozes, 2010. 